\title{
A CDA Approach to the Representation of Cultures and Ideologies through Translated Political Texts: A Case Study of "All the Shah's Men: An American Coup and the Roots of Middle East Terror" by S. Kinzer
}

\author{
MOHAMMAD AMIN EBRAHIMI FARD (corresponding author) \\ School of Languages, Literacies and Translation \\ Universiti Sains Malaysia \\ amin.ebrahimifard@gmail.com
}

\begin{abstract}
Translation, as a social and linguistic phenomenon, had been investigated from various viewpoints by scholars with different backgrounds. This paper aims at investigating the ideological impacts of the process of translation and its consequences on the representation of ideologies and cultures. In pursuing this goal, Critical Discourse Analysis (CDA) was found to be an accommodating tool. The theoretical structure of this research is based upon Fairclough's (1989, 1995) \& Farahzad's (2007) framework. The corpus used for analysis in this research is a book and its corresponding Persian translation. The case study of this research is All the Shah's Men: An American Coup and the Roots of Middle East Terror by Stephen Kinzer (2003) translated by Shahryar Khavvajian. Examining the text and its translation from the perspectives of macro level \& micro level illuminated the fact that the translator employed different devices to change the ideological positioning of the source texts and deviate the readers from the route they might have taken through reading the ST toward the one they presumed it was more ideologically efficient regarding the community the book was translated for. In other words, the power and ideologies have clearly influenced the translation, comparing the source text with the target one which is completely diverged as the situation, policies and preferred politics asked for. Translated texts appeared in a context different from that of the source texts. A text is produced in the context of "Self" and is translated in the setting of "Other" or at least for "Other".
\end{abstract}

Keywords: Critical Discourse Analysis (CDA), Culture, Ideology, Power, Translation quality

Published online: 30 April 2020

To cite this article: Fard, M. A. (2020). A CDA Approach to the Representation of Cultures and Ideologies through Translated Political Texts: A Case Study of "All the Shah's Men: An American Coup and the Roots of Middle East Terror" by S. Kinzer. International Journal of Language, Literacy and Translation 2(2), 1-9. https://doi.org/10.36777/ijollt2020.3.1.029

To link to this article: https://doi.org/10.36777/ijollt2020.3.1.029

This work is licensed under the terms of the Creative Commons Attribution (CC BY) (https://creativecommons.org/licenses/by/4.0/). 


\section{INTRODUCTION}

\section{GENERAL OVERVIEW}

Translation has been practiced from the very beginning of human history. In Perez's words "it is as old as human kind"(2003, p. 10). Translation has also been discussed from various viewpoints such as linguistic, philosophical, social, and many more. The reason is that the act of translation is involved in more than language and it always takes place in the cultural and political systems, as well as in history. Translation studies (TS) owe its development more than anything else to James S. Holmes whose prominent essay, "the name and nature of translation studies", was lectured at the Third International Congress of Applied Linguistics in Copenhagen in 1972 (Munday, 2001, p. 10). Critical Discourse Analysis (CDA), which tries "to read the traces and effects of power in language and discourse, in text and syntax" (Hodge \& Kress, 1993, p. 153) is one of these tools. Perez reflects the idea of CDA scholars while stating that " all language use is ideological" (2003, p. 4), and since translation, as a linguistic and social phenomenon, is carried out on language use, it can be a manifestation of ideological encounters too.

\section{STATEMENT OF THE PROBLEM}

This research makes use of a method based on Critical Discourse Analysis (CDA) to investigate the effects of the process of translation on representation of source text and its author's ideological position. The present study takes one political work into consideration. The book under scrutiny is around the close analysis of Stephen Kinzer's All the Shah's Men: An American Coup and the Roots of Middle East Terror (2003). Kinzer, an American journalist, discusses the 1953 Iranian coup d'état backed by the U.S. Central Intelligence Agency (CIA) in which Mohammed Mossadegh, Iran's prime minister was overthrown. This book was translated by Shahryar Khavajian. Setting up this political work as the established corpus of the present study, the researcher uses CDA to investigate the ideological impact of the process of translation. With recourse to this critical translation approach, the researcher tries to find out how translation changes or modifies the ideological status of translated texts and consequently represents the source text's author and cultures differently. The novelty of the study is to investigate the effect of power and politics on the quality of translation in Middle East based on CDA approaches.

\section{THEORETICAL FRAMEWORK OF THE STUDY}

This study employed Farahzad's CDA model as its theoretical framework. According to Hodge and Kress, "the signs of syntax always ideologically inflected social meanings" (1993, p. 208). Selection of one linguistic element and preferring it to another option may reveal the ideological position of translators as it has already disclosed its author's status. Hodge and Kress (1993, p. 15) recognize selections as ideologically loaded practices, which determine the representation of reality. Fairclough (1995) believes scholars with various backgrounds can use Critical Discourse Analysis, as an interdisciplinary tool. Therefore, Farahzad's model of CDA (2007) which is based on Fairclough's theoretical foundation of CDA was selected as a 
framework to explore the probable ideological effects of the modifications made in the translated texts and reveal their impact on representations of reality. However, due to the fact that CDA encompasses numerous fields, this research only focuses on the cultural and ideological standpoints and will be given full consideration.

The linguistic approach applies descriptive studies focusing on textual forms and fails to address ideological issues. Cultural approach, for its part, targets these issues but has no methodical formal framework of analysis. Critical Discourse Analysis (CDA), and especially Farahzad's model thereof, can play this role for a systematic analysis because of its interdisciplinary tools and common theoretical background. The act of translation is not a purely linguistic activity; translators must attend to the political, social, and ideological backgrounds of writers to be able to render a message from source to target language. Due to the fact that translation encompasses the close links between language and culture, CDA researches carried on in Translation Studies aim at analysing the translated texts to realize how much the ideology of writers is visible in the translated texts, and to what extent ideological standing of the translators affect the process of translation and renditions (Venuti, 1998).

Table 1

Farzaneh Farahzad's Model on CDA

Translation Criticism

\begin{tabular}{cl}
\hline Micro Level & Vocabulary, Grammar, Multimodal Elements \\
\hline Macro Level & Translator's judgment, Categorization and classification, \\
& Representation of reality, Power relation, Ideologies, Implications \\
\hline
\end{tabular}

\section{RESEARCH QUESTION}

1. To what extent does the translator change the ideological position of Kinzer's "All the Shah's Men: An American Coup and the Roots of Middle East Terror" with recourse to Farahzad's Translation Criticism Model?

\section{REVIEW OF THE LITERATURE}

\section{INTRODUCTION}

Critical science in each area asks questions such as those of responsibilities, interests, and ideologies; and instead of focusing on purely academic or theoretical problems, it starts from existing social problems, and in doing so it chooses the view point of those who suffer the most, and seriously analyze those in power, those who are responsible, and those who have the resources and the opportunity to resolve such problems Van Dijk cited in (Wodak \& Meyer, 2001, p. 1). 
The 1970s saw the appearance of a form of discourse and text analysis as recognition of the role of language in structuring power relations in society. At that time, much linguistic research elsewhere was focused on formal aspects of language which represented the linguistic competence of speakers and which could theoretically be isolated from specific instances of language use (Wodak \& Meyer, 2001, p. 5). Attention to texts, their production and interpretation and their relation to societal impulses and structures indicated a very different kind of interest in the works of some prominent scholars afterwards serves to explain and illustrate the main assumptions, principles and procedures of what had then become known as CL. Kress 1979 (in Wodak \& Meyer, 2001, p. 11) gave an account of the theoretical foundations and sources of critical linguistics and indicated that the term CL was quite selfconsciously adapted from its social-philosophical counterpart, as a label by the group of scholars working at the University of East Anglia in the 1970s. By the 1990s, the label CDA came to be used more consistently with this particular approach to linguistic analysis.

\section{METHODOLOGY}

\section{INTRODUCTION}

There are many different methods in Critical Discourse Analysis (CDA) investigations. These wide variety of theories, range from micro-sociological perspectives to theories on society and power, theories of social cognition and grammar, as well as individual concepts that are borrowed from larger theoretical traditions cited in (Wodak \& Meyer, 2001, p. 17).

The present chapter introduces the type of research, the corpus of the study, as well as the data collection and analysis method.

\section{RESEARCH DESIGN}

CORPUS

This paper is a corpus-based descriptive-explanatory comparative study of written texts between English and Persian languages.

As mentioned before, the corpora chosen is Stephen Kinzer's (2003) "All the Shah's Men: An American Coup and the Roots of Middle East Terror" which is translated by Shahryar همa مردان شاه "كودتاى امريكايى و ريشه هاى ترور در خاورميانه" Khajian (2004) and entitled

This book discusses the significant role of CIA in overthrowing Mossadegh, Iran's prime minister and backing the 1953 Iranian coup d'état.

\section{PROCEDURE}

The corpus of the study was segmented into four parts: the source book mentioned in the last part and their translation. The data was collected based on the method described below and was analyzed for the purpose of determining the ideologically significant strategies. The dominant unit of analysis was sentence unless more than one sentence was required to make equivalence relation between corresponding units.

\section{DATA COLLECTION}

The whole investigation revolved around applying Farahzad's model of CDA to the chosen text. Since CDA generally and Farahazad's model of CDA specifically are mostly applied on 
political genre, “All the Shah's Men: An American Coup and the Roots of Middle East Terror"” and its translation which are chosen to be investigated here fall under the category of political text by critics. CDA demands the close analysis of this text via the detailed examination of sentences in both the original books and the translated one.

The book under analysis is "All the Shah's Men: An American Coup and the Roots of Middle East Terror". Regarding the mentioned book the whole source text (ST) and its corresponding translation were studied. During the investigation $30 \%$ of the whole sentences were rigorously examined by the advisor of the present research in order for the validity of the research to be fulfilled.

INSTRUMENT AND DATA ANALYSIS

Upon data collection, Farahzad's 2007 CDA-based model of translation criticism was employed in a comparative analysis to analyze the translation, and to determine the possible ideological position of the translator. Farahzad's model and the way it was applied on the aforementioned work are elaborated below:

MICRO LEVEL

Vocabulary

The words related to both USA and Britain was searched in both Kinzer's All the Shah's Men: An American Coup and the Roots of Middle East Terror and its corresponding translation by Khavvajian.

Grammar

What kinds of processes predominate and what are their corresponding roles in the target text (TT)? Is agency clear or not?

Are sentences active or passive and how are they rendered?

MACRO LEVEL

Analysing Translator's Judgments

This analysis was carried out on the basis of prefaces, footnotes, and/or endnotes of prototexts and meta-texts, Since All Shah's men, translated in Iran.

Translation Strategies

The translation strategies were investigated to see what ideological implications they might have. The strategies considered to be applied on the abovementioned book were the ones mentioned in Farahzad's model and they are as follows: Borrowing, Calque, Addition or Overwording, Undertranslation, Omission, Substitution / Alteration, explicitation, Selection of Parts from Wholes, Rearrangement of Sentence Elements. The number of strategies applied in the translation of the book is brought in the next section.

DATA SHEET

The first type presents the number of verbs, types of the verbs used, as well as the number of key words and information related to them. 


\begin{tabular}{lcc}
\hline $\begin{array}{l}\text { All the Shah's Men: An } \\
\text { American Coup and the Roots } \\
\text { of Middle East Terror }\end{array}$ & ST & TT \\
\hline Total verbs & & \\
\hline Actional & 4750 & 5420 \\
\hline Relational & 3910 & 3960 \\
\hline Passives & 840 & 1460 \\
\hline Key word related usage & 260 & 180 \\
\hline Key word as direct agent & 326 & 372 \\
\hline
\end{tabular}

The second type of the tables was used to portray the strategies used during translation by the translator, as well as the number of their usage and their percentage.

Table 3

Sample of strategies

\begin{tabular}{lcc}
\hline $\begin{array}{l}\text { Strategies applied in analyzed } \\
\text { text }\end{array}$ & ST & TT \\
\hline Omission & 6 & 15 \\
\hline Substitution & 20 & 52 \\
\hline Explicitation & 4 & 11 \\
\hline Mistranslation & 0 & 0 \\
\hline Addition & 4 & 11 \\
\hline Under translation & 4 & 0 \\
\hline Borrowing & 0 & 0 \\
\hline Calque & 0 & 0 \\
\hline $\begin{array}{l}\text { Rearrangement of sentence } \\
\text { element }\end{array}$ & 0 & 0 \\
\hline Selection of parts from wholes & 0 & 100 \\
\hline Total number of strategies & 38 & \\
\hline
\end{tabular}

\section{FINDINGS}

In the present paper, the book specified in the corpus was analysed in a comparative study at three levels of textual, paratextual and semiotic as suggested by Farahzad (2007). At the textual level, the in-text strategies used by the translator in translation of the selected text from the book are analyzed for determining their ideological significance. At the paratextual level, any available footnote, endnote, foreword or introduction is analyzed. At the semiotic level, the cover image as well as any pictures or figures are analyzed for determining the ideological value and alignment with the dominant ideologies in Iran. These levels were carried out separately on the selected corpus element.

\section{MICROLEVEL ANALYSIS}

Vocabulary

One question regarding vocabulary had been examined in this research:

Are there any words and expressions used in the metatext which are ideologically significant? What role do they play in their corresponding TT? 
Considering the book "All the Shah's Men : An American Coup and the Roots of Middle East Terror" two key words of "USA" and all the words in relation to this word and also "Britain" and all the words pertinent to it was considered to be investigated. This is because this book was totally dedicated to describe the pivotal role of the USA and Britain in overthrowing Mohammad Mosaddegh. The first key term (USA) was repeated 326 times in the source text and 372 times in the target text. Repeating the word Britain and its related words 493 times in the source text depicts the role of Britain even stronger than America in the 1953 Coup in Iran which burned fifty years of effort to reach democracy into ashes. This word was repeated $\mathbf{5 6 2}$ times in the TT (Table 4.2). Both key terms and the words related to them were repeated more than the times in the TT which illustrates that they become more visible in the eye of the translator.

\section{Grammar}

In the second level of this research the grammar of the texts was scrutinized. This paper focused on process types and agency and the voice of sentences to see whether they were active or passive. The questions in this regard were:

What kinds of processes predominate in the ST and TT? Is agency unclear?

How many percent of the sentences are active or passive in the Persian and English texts?

To find the answer to the first question, what was mentioned earlier in chapter two from Kress and Hodge about processes had been taken into consideration. In short, they categorize processes into two types: "actionals" and "relational". Actionals are those verbs which indicate the actions. Relational on the other hand are used to classify and attribute adjectives (1996, p. 39).

In the investigation of vocabularies of "All the Shah's Men: An American Coup and the Roots of Middle East Terror" the word USA and all of the words which somehow pointed to this country and their derived forms were examined. There were $\mathbf{3 2 6}$ uses of such words in the ST and 372 times in the TT. In the ST these words had been direct agents or part of the agent of actional processes for $\mathbf{2 1 6}$ times while in the TT this became 248; moreover, the term Britain and its related words were repeated 493 times in the ST while they were repeated $\mathbf{5 6 2}$ times in the TT. In the ST these words played roles as direct agents for $\mathbf{3 8 8}$ times while the same words in the TT appeared 412 times as direct agents (Table 4.2). This depicts that in the TT, USA and Britain were more responsible for actions. Considering the content of the text which was based on the fact that these two countries were directly responsible for the Coup to oust Mosaddegh in Iran, it became interesting that the translator had put more burden of responsibility on the shoulders of USA and Britain and had let the readers blame them more easily.

\section{Passive Transformation}

In the book, "All the Shah's Men: An American Coup and the Roots of Middle East Terror", this trend was obvious as there were $\mathbf{2 6 0}$ passives out of $\mathbf{4 7 5 0}$ processes (about $\mathbf{6}$ percent of the total amount). In the translated text there were 180 passives out of $\mathbf{5 4 2 0}$ processes (around 2 percent). These numbers showed that both the translator and author had chosen the antimystification strategy to show what the United States was performing in its ongoing relations with the rest of the world. But a delicate difference was evident in this book and its corresponding translation regarding the former book, i.e. passives had reduced by around 4 percent in the TT. It was already mentioned that the second book was entirely dedicated to 
show what America and Britain had done and were doing in their ongoing deeds inside and outside their borders and the majority of 'agents' directly or indirectly referred to the USA and Britain or their administrative institutions like CIA and MI6. By decreasing the number of passives, once again the USA and Britain became more responsible for their actions and evilness in the TT.

Unlike the author whose context was US community and may have taken some matters into consideration by not talking more vividly the translator was in a totally different context. He did not feel any problem to reveal whatever was regarded as bad deeds against America and Britain so they had used active mode more generously instead of passives.

Table 4

Sample of verbs

\begin{tabular}{lcc}
\hline $\begin{array}{l}\text { All the Shah's Men: An American } \\
\begin{array}{l}\text { Coup and the Roots of Middle } \\
\text { East Terror }\end{array}\end{array}$ & ST & TT \\
\hline Total verbs & 4750 & 5420 \\
\hline Actional & 3910 & 3960 \\
\hline Relational & 840 & 1460 \\
\hline Passive & 260 & 180 \\
\hline Total USA related usage & 326 & 372 \\
\hline USA as a direct agent & 216 & 248 \\
\hline Total Britain related usage & 493 & 562 \\
\hline Britain as a direct agent & 388 & 412 \\
\hline
\end{tabular}

\section{MACROLEVEL ANALYSIS}

Translators' judgments

In the preface of the book "All the Shah's Men: An American Coup and the Roots of Middle East Terror" written by Stephen Kinzer who is a veteran New York Times correspondent and has reported from more than fifty countries on five continents, we are facing someone who is in the US context and is trying to elaborate on the matter why the outlook of people outside the borders of the US is gloomy toward America. Looking at the following sentence which are told by an Iranian woman, we figure out the main mission of Kinzer writing this book is to go into the detail of the reasons why other countries mistrust the USA, so that this would never happen in the future and America would gain the trust of other nations back and become the godfather everyone expects.

The TT did not have a constructive role as the original one but it followed a destructive role to darken the picture of the 'greatest enemy'. Here the book and its translator were located in the culture of those people who might hate America, not that of 'America' which is the subject of hatred and that of the authors. In the preface to the translated book which is published by "Markaz-e Asnad-e enghelab-e eslami" the Center of Islamic Republic Documents, one of the governmental dependent organizations, in Iran.

\section{Translation Strategies}

In the translation of "All the Shah's Men: An American Coup and the Roots of Middle East Terror" by Stephen Kinzer, Khavajian used different translation strategies. Since the translation of the present book published in the Islamic Republic of Iran (I.R.I) and it revolved around the political atmosphere before and after nationalization of oil in Iran and the political figures and parties those days, the aforementioned strategies were employed consciously by 
the translator to apply the comprehensive doctrine of I.R of Iran. Here come the cases on which the investigation of translation strategies has taken place and is divided based on each strategy:

Table 5

Sample of strategy

\begin{tabular}{lll}
\hline Strategies applied in the translation of All the & Number & Percentage (\%) \\
Shah's Men: An American Coup and the & & \\
Roots of Middle East Terror & & \\
& & 15 \\
\hline Omission & 6 & 52 \\
\hline Substitution/Alteration & 20 & 11 \\
\hline Explicitation & 4 & 0 \\
\hline Mistranslation & 0 & 11 \\
\hline Addition & 4 & 11 \\
\hline Undertranslation & 4 & 0 \\
\hline Borrowing & 0 & 0 \\
\hline Calque & 0 & 0 \\
\hline Rearrangement of sentence element & 0 & 0 \\
\hline Selection of parts from wholes & 0 & 100 \\
\hline Total number of strategies & 38 & \\
\hline
\end{tabular}

\section{DISCUSSION AND CONCLUSION}

This research revealed the importance of consciousness of translators about power relations in their society and in the world. Translators should be aware about what goes on in the deeper layers of texts and show a due and expedient response to them in their translation act. In Fairclough's words (1995, p. 18), they should gain 'critical language awareness'. This does not happen unless they know how to analyze a text for translation. Critical Discourse Analysis gives them this opportunity to become aware of the underlying layers of texts and play due role in the power relations through the process of translation.

Considering the book "All the Shah's Men: An American Coup and the Roots of Middle East Terror" two key words of "USA" and all the words in relation to this word and also "Britain" and all the words pertinent to it were considered to be investigated. This is because this book was totally dedicated to describe the pivotal role of the USA and Britain in overthrowing Mohammad Mosaddegh. The first key term (USA) was repeated 326 times in the source text and 372 times in the TT. Repeating the word Britain and its related words 493 times in the source text depicts the role of Britain even stronger than America in the 1953 Coup in Iran which burned fifty years of effort to reach democracy into ashes. This word was repeated 562 times in the target text. Both key terms and the words related to them were repeated more than the times in the TT which illustrates that they become more visible in the eye of the translator. It became apparent that in the translated book the substitution/ alteration strategy was employed more than other strategies which were $52 \%$.

Examining the text and its translation from two perspectives of microlevel and macrolevel illuminated the fact that the translator employed different devices to change the ideological positioning of the source text and deviates the readers from the route they might have taken 
through reading the ST toward the one they presumed was ideologically more efficient regarding the community the book was translated for.

From increasing the number of key words like USA as direct agent in the TT, to deleting even one whole page from the ST in the process of rendering, to substituting different parts of the ST with the ones the translators and their publications deem more appropriate to the ideological atmosphere of the TT and all other deviations from the original path of the STs, it becomes evident that since both books were published in Iran and even by a governmental organization, most of the deviations were intentionally employed. As a result, it is completely clear that the power and politics affect the quality of translation and translator's job in a way that it will be accepted by the publisher to be published and the translators themselves would not face any problem.

This research was motivated to investigate linguistic and paralinguistic elements in translated books to find out if translation changes the ideological positioning of source texts and if CDA can be used to discover the ideological implications of such probable deviations, which might have occurred intentionally or unintentionally in Translated Texts. In pursuing these objectives, translated texts appeared in a context different from that of the source texts. A text is produced in the context of "Self" and is translated in the setting of "Other" or at least for "Other".

\section{REFERENCES}

Fairclough, N. (1989). Translation, Power, Subversion. Clevedon: Multilingual Matters.

Fairclough, N. (1995). Language and Power: London: Longman Critical Discourse Analysis. Boston: Addison Wesley.

Farahzad, F. (2007). Translation Criticism. Bokhara, No. 62. Tehran.

Fawcett, P. (2003).The Manipulation of Language and Culture in Film Translation. In M. C. Perez (Ed.), Apropos of Ideology: Translation Studies on Ideology - Ideology in Translation Studies (pp. 145-163) Manchester: St. Jerome.

Hodge, R. \& Kress, G. (Eds.). (1993). Language as Ideology. New York: Routledge.

Kinzer, S. (2003). All the Shah's Men an American Coup and the Roots of Middle East Terror. John Wiley \& Sons, Inc., Hoboken, New Jersey.

Kress, G. \& Leeuwen, T.V., (Eds). (2001). Multimodal Discourse: The Modes and Media of Contemporary Communication. London: Arnold Press.

Kress.G \& Hodge. R (1996). Language as ideology, Routledge, London.

Munday, J. (2001). Introducing Translation Studies: Theories and Applications. London: Routledge.

Schiffrin, D. \& Hamilton, H. (Eds.). (2001). The Handbook of Discourse Analysis.

Wodak, R. \& Meyer, M. (Eds.). (2001). Methods of Critical Discourse Analysis. London: Sage Publications. https://doi.org/10.4135/9780857028020

Venuti, L. (Ed.). (1998). The Translation studies reader. London and New York: Routledge.

\section{Persian References}

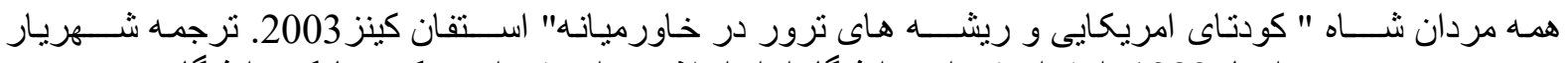

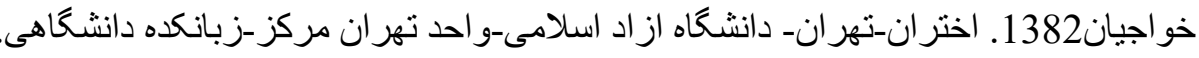

Kinzer, S. (2003). All the Shah's men. A Translation by Shahriar Khajian) 2003). Islamic Azad University of Tehran, AKhtaran Press. 